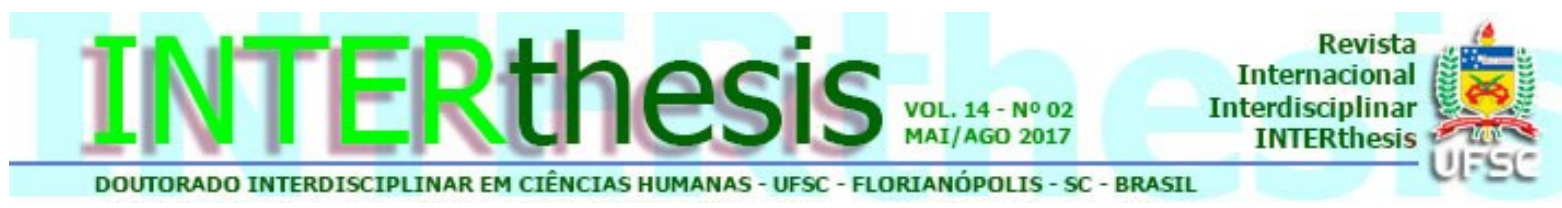

\title{
A INVISIBILIDADE SOCIAL E POLÍTICA DOS AGRICULTORES FAMILIARES E SEUS REFLEXOS NAS RELAÇÕES COM O ESTADO
}

\section{Resumo:}

Marlene de Paula Pereira ${ }^{1}$

Maria Izabel Vieira Botelho

O presente artigo tem por objetivo fazer uma reflexão a respeito da invisibilidade social e política de alguns segmentos sociais, dentre os quais se destacam os agricultores familiares, e sobre os reflexos dessa invisibilidade na seara jurídica, visto que este segmento, com frequência enfrenta embates judiciais em decorrência do descumprimento da legislação ambiental. A metodologia empregada no trabalho foi a consulta aos arquivos do Ministério Público da Comarca de Viçosa - MG e análise processual. Conclui-se, com o trabalho que a invisibilidade social e política se estende para a área jurídica porque tais grupos sociais encontram dificuldades de acesso não apenas à informação, mas também aos mecanismos de defesa.

Palavras chave: Invisibilidade. Agricultores familiares. Estado. Poder. Legislação.

\section{INTRODUÇÃO}

No contexto do Estado Democrático de Direito existe o pressuposto de que as relações entre população e Estado sejam justas e igualitárias. Apesar disso, diversas são as situações em que se nota que grupos social e economicamente mais vulneráveis encontram dificuldades em verem seus direitos respeitados e suas garantias asseguradas.

O presente artigo tem o objetivo de fazer uma reflexão a respeito da condição de vulnerabilidade desses grupos, a partir de um estudo empírico em que se buscou identificar a real condição dos agricultores familiares em relação à lei ambiental e a todos os desdobramentos decorrentes de seu descumprimento.

Apesar da grande divergência existente a respeito do conceito de "agricultura familiar", o termo que está sendo utilizado neste texto vai ao encontro do que Van Der Ploeg (2009) chama de "agricultura camponesa", segundo o qual, uma parte da produção é vendida, e a outra parte é usada para a reprodução da propriedade e da família.

\footnotetext{
${ }^{1}$ Doutoranda em Extensão Rural na Universidade Federal de Viçosa, Viçosa, MG. Professora de Direito do Instituto Federal de Ciência e Tecnologia do Sudeste Minas Gerais, Barbacena, MG, Brasil E-mail: depaulamarlene@yahoo.com.br

2 Doutora em Sociologia pela Universidade Estadual Paulista Júlio de Mesquita Filho. Professora da Universidade Federal de Viçosa, Viçosa, MG, Brasil. E-mail: mbotelho@ufv.br
} 
Navarro e Pedroso (2014) afirmam que, no imaginário coletivo, agricultura familiar é sinônimo de pequena produção rural e, por isso, engloba os estabelecimentos produtores das rendas mais baixas e, também, aqueles de menores tamanhos de área. Sociologicamente, seria o vasto contingente social que possui acesso precário, parcial ou insuficiente aos meios de produção, como terra e capital produtivo, assim como informações e canais de escoamento de sua produção excedentária (SCHNEIDER e NIEDERLE, 2008).

Desse modo, todos os agricultores familiares entrevistados para a pesquisa possuíam entre 6 e 25 hectares de terra; apresentam um perfil agrícola bastante diversificado, produzindo tudo ou quase tudo de que necessitam; gerenciam a propriedade ao mesmo tempo em que representam a principal mão de obra.

A metodologia empregada na pesquisa envolveu dois eixos: um, realizado no Ministério Público da Comarca de Viçosa- $\mathrm{MG}^{3}$, em que foi feito uma pesquisa de caráter quantitativo, com consulta ao sistema interno de computação do órgão. Por meio deste trabalho pôde-se quantificar as principais ocorrências em cada município estudado e verificar o desfecho judicial/extra judicial que cada uma apresenta, o estágio em que se encontra o processo, quais eram as partes envolvidas. Ainda no Ministério Público, foram realizadas consultas aos autos processuais. Estas consultas permitiram uma análise mais acurada e qualitativa, em que se pôde perceber como ocorre a marcha processual nesses casos, quais são as exigências da justiça e quais são as principais dificuldades encontradas pelos agricultores.

Foram analisados 148 processos/procedimentos ambientais (Termos de ajustamento de conduta, inquéritos civis, ações civis, ações penais). Chegou-se ao número 148 de processos por meio do cálculo da amostra válida que considerou a totalidade de processos em curso no período de 2011 a 2013, equivalente a 240 processos. Neste cálculo considerou-se o erro amostral em $5 \%$ e o nível de confiança em 95\%.

Por meio de um estudo detido de cada um dos processos foi possível compreender as causas que deram origem ao processo, o nível econômico-social desses agricultores, o tratamento dado pelos órgãos públicos a esses produtores, o que a Justiça propôs e o que foi efetivamente realizado. Todo o levantamento de dados desta pesquisa foi realizado na Comarca de Viçosa - MG.

${ }^{3}$ A Comarca de Viçosa- MG é composta por seis municípios. São eles: Viçosa, Coimbra, Cajuri, São Miguel do Anta, Porto Firme e Paula Cândido. Todos localizados na região da zona da mata mineira. R. Inter. Interdisc. INTERthesis, Florianópolis, v.14, n.2, p.113-131 Mai.-Ago. 2017 
O recorte temporal de 2011 a 2013 foi realizado tendo em vista o ano de aprovação do atual Código Florestal (2012), que é uma lei que interfere diretamente na vida dos agricultores familiares, sendo responsável por mais de $90 \%$ dos processos ambientais em curso. Assim, buscou-se analisar processos anteriores e posteriores à referida lei, com vistas a constatar mudanças ou mesmo fazer comparações.

O segundo eixo metodológico baseou-se na realização de entrevistas semiestruturadas. Foram entrevistados 25 agricultores familiares que desenvolvem suas atividades em um dos seis municípios que compõem a Comarca de ViçosaMG. O objetivo da realização de algumas entrevistas foi levantar dados que fossem relatados por aqueles que se encontram diretamente sob a ameaça lei, pois, nos processos judiciais, as falas das pessoas são adequadas pelo escrivão. Trata-se de uma "tradução" e não apenas de uma "transcrição". As entrevistas são capazes de oferecer a informação viva.

O artigo está organizado em duas partes, na primeira, será apresentada a discussão teórica a respeito do direito como instrumento de poder, e, na segunda, serão apresentados dos dados da pesquisa e outras discussões utilizadas como suporte para a interpretação dos resultados obtidos.

\section{O DIREITO COMO INSTRUMENTO DE PODER E DE LIBERDADE}

O Estado democrático de direito caracteriza uma situação jurídica em que todos, inclusive o Estado, estão submetidos à hierarquia das leis. Segundo Sunfeld (2006, p. 55), o Estado de direito é aquele criado e regulado por uma Constituição, onde o exercício do poder político seja dividido entre órgãos independentes e harmônicos, que controlem uns aos outros, de modo que a lei produzida por um deles tenha de ser necessariamente observada pelos demais e que os cidadãos, sendo titulares de direitos, possam opô-las ao próprio Estado.

As bases do Estado de direito foram consolidadas no século XIX, com o fim do Estado absolutista e a submissão do poder político ao direito. Também no século XIX surge o positivismo jurídico. O positivismo jurídico identifica o direito com um conjunto de normas postas pelas autoridades que possuem o poder político de emaná-la: "justo é o que está conforme a lei e injusto é o que está em desacordo 
com ela". Segundo esta corrente de pensamento, os requisitos para verificar se uma norma pertence ou não a um dado ordenamento jurídico têm natureza formal, vale dizer, independem de critérios de mérito externos ao direito, decorrentes de outros sistemas normativos, como a moral, a ética ou a política. Assim, uma regra pertencerá ao sistema jurídico, criando direitos e obrigações para os seus destinatários, desde que emane de uma autoridade competente para a criação de tais normas e desde que seja criada de acordo com o procedimento previsto legalmente para a edição de novas normas, respeitados os limites temporais e espaciais de validade (BOBBIO, 1995).

Entretanto a segunda guerra mundial representou um marco na mudança desse paradigma, pois as atrocidades cometidas neste período encontravam fundamento na lei. Assim começaram a surgir correntes que afirmavam que "a vida moral não podia reduzir-se a formas, por mais seguras que estas fossem" (BOBBIO, 1995). O positivismo jurídico deu lugar, então, a uma nova corrente filosófica, o póspositivismo, que serviu de apoio para o surgimento da corrente neoconstitucionalista do direito. Dentre as principais características do neoconstitucionalismo, destaca-se a ideia da eficácia valorativa da Constituição, ou seja, todas as facetas do neoconstitucionalismo objetivam, em maior ou menor grau, extrair o sentido valorativo do texto constitucional, fundado, principalmente, na dignidade humana (BARROSO, 2014).

A partir de então, a separação total entre o direito e a moral foi relativizada, os valores sociais passaram a ser entendidos como parte da norma jurídica e a interpretação ganhou nova roupagem, possibilitando ao juiz agir no sentido de buscar parâmetros de justiça e equidade, e não mais atuar apenas como "a boca da lei".

Streck (1998) explica que no Estado democrático, a função do direito é ser instrumento transformador da realidade. Segundo ele, os vínculos no Estado democrático de direito são materiais e impedem a preponderância da concepção de democracia vinculada à vontade da maioria, em franca opressão à minoria. Assim, as noções de direitos fundamentais e de democracia irradiam sua influência por todas as suas instituições políticas e jurídicas.

Neste contexto, destaca-se ainda como elemento fundamental do Estado democrático de direito, a garantia da participação paritária na vida cotidiana e na 
vida pública, de modo que todos possuam direitos iguais e tenham oportunidades iguais. Com essa mudança de paradigma, o direito, então, deixa de ser visto como um conjunto de normas e passa a abarcar os fatos a ele subjacentes e os valores e ideologias que o condicionam (LEMOS, 2011). Questiona-se, cada vez mais, a legitimidade da norma, ou seja, mais importante do que o procedimento de elaboração, são os fundamentos da norma, a sua interpretação e a sua aplicação.

O nível de eficácia social ou efetividade da norma depende, dentre outros fatores, da compreensão da população a respeito da lei. A lei deve ser o elo entre o Estado e o cidadão, portanto, é preciso ter sempre em mente que a norma é feita para a sociedade e não para os especialistas (DUTRA, CONPEDI, 2006). Por vezes, somos levados a acreditar que a causa da inefetividade da norma é a conduta dos destinatários, mas se a norma não estiver de acordo com a realidade do indivíduo, com o contexto social e econômico em que ele está inserido, não haverá cumprimento, porque não haverá reconhecimento. O reconhecimento ocorre à medida que o cidadão se identifica com a norma. Quando o direito é reconhecido, ele incorpora-se à maneira de ser e agir da coletividade.

A pesquisa empírica realizada para este trabalho demonstrou que os agricultores familiares não conhecem bem a legislação ambiental, embora sejam diretamente atingidos por ela. Esta é uma das razões que levam ao descumprimento. Além disso, encontram dificuldades para se valerem de mecanismos e recursos legais que o ordenamento jurídico disponibiliza. Nesse sentido, é possível pensar que, em alguns casos, o direito funciona como um instrumento de poder.

\section{O DIREITO NO PAPEL E NA PRÁTICA}

O direito, por si só não é instrumento de poder e nem de liberdade. Tudo depende do uso que se faz dele. Thompson (1987) ao buscar compreender a origem e o significado da Lei Negra (1723) na Inglaterra, explica como a lei pode funcionar como uma estrutura de poder. Esta lei visava conter as ações de caçadores clandestinos que, reivindicando usos costumeiros consolidados, transpunham as fronteiras dos parques e florestas da Coroa e de lá retiravam produtos silvestres. $\mathrm{O}$ objetivo de Thompson (1987) estava embasado na constatação da importância da lei 
na história jurídica do século XVIII, de preservar a propriedade privada e assegurar interesses de grupos fortes.

Segundo Thompson (1987, p. 351), a lei pode ser considerada uma instituição, mas também uma ideologia. Para o autor, não se pode acreditar na imparcialidade abstrata da lei, pois ela pode ser também um instrumento de dominação. Nessa mesma linha de pensamento, Santos (2003, p.63), ao refletir se o se o direito é ou não emancipatório, conclui que o direito não é "emancipatório", nem tampouco "não emancipatório", ou seja, ele pode tanto aprisionar, quanto libertar. Quem atribui ao direito o caráter de libertador ou de aprisionador são os grupos ou instituições que fazem uso dele. Segundo Santos (2003, p. 12), o direito oficial faz parte de um vasto conjunto de recursos políticos, ou seja, o que é permitido é o que está de acordo com os interesses dos grupos que estão por trás do Estado. O que não está de acordo com tais interesses é considerado ilegal. Assim, muitas vezes, "o direito oficial" não consegue captar a experiência de vida do indivíduo e, assim, tais experiências transformam-se em práticas ilegais.

Para Santos (2003, p. 15), muitas dessas práticas são, na verdade, legalidades alternativas, modalidades de direito que surgem no contexto doméstico, no contexto do trabalho, no contexto da cidadania, mas que foram tidas como irrelevantes quando da criação do direito oficial, pelo Estado. Nesse sentido, percebe-se a incapacidade do direito de ser instrumento de emancipação social, na medida em que reconhece os interesses de alguns grupos, mas exclui o de outros, que, não conseguem se fazer representar. Por não encontrarem identificação com a formulação jurídica e por não possuírem acessos aos meios que poderiam auxiliálos, tais grupos a desconsideram, passando então a ocuparem lugar na ilegalidade. A ausência das reivindicações de tais grupos nos textos das leis deve-se ao fato de serem estes indivíduos cidadãos do ponto de vista formal, mas se encontrarem excluídos dos processos democráticos.

\subsection{DADOS EM CENA}

De acordo com o estudo empírico realizado, na Comarca de Viçosa, durante o período de 2011 a 2013, considerando os 240 procedimentos em curso, 65,8\% resultaram em acordos denominados "Termo de Ajustamento de Conduta" (TAC). 
Destes, $33,5 \%$, foram cumpridos e $66,5 \%$ tiveram desdobramentos judiciais, com propositura de ações. Logo, não se pode afirmar que a realização do acordo extrajudicial tenha amenizado a situação do agricultor, evitando que este tenha desgastes decorrentes da lentidão e burocracia da Justiça, pois a quantidade de acordos que não foram cumpridos é grande. As principais razões que justificam o descumprimento dos TAC são as dificuldades em cumprir as medidas e o custo que elas envolvem.

Quanto ao período médio para a questão seja solucionada por meio de TAC, observou-se que entre a ocorrência do fato e a realização do acordo decorrem, em média, 2 anos. Entre a realização do TAC e o termo final do processo decorrem, em média, 3 anos, totalizando um período de duração médio para o processo de 5 anos, desconsiderando eventuais recursos. Esse prazo pode variar de acordo com as especificidades do caso, mas o que se pôde notar é que o fator que mais interfere no tempo de duração do processo é a realização da perícia. De acordo com informações obtidas nos próprios autos e confirmadas por funcionários estaduais, a estrutura dos órgãos técnicos estaduais responsáveis pela perícia encontra-se bastante deficitária, de modo que os agentes são insuficientes para o número de solicitações feitas pela Justiça.

Com o problema de falta de profissionais para atender a um número grande de demandas, os processos se arrastam nos gabinetes aguardando um parecer. Diante da atual situação dos órgãos públicos estaduais, o próprio Ministério Público, quando percebe que o infrator tem condições de arcar com o custo, determina que a perícia seja feita às suas expensas. Em geral, são necessárias duas perícias, uma no início, para averiguar se houve dano, estimar o tamanho do dano e apontar as medidas a serem tomadas seja para a recuperação do ambiente ou, se isto não for possível, para indicar as medidas compensatórias. E, outra, no final do processo, para verificar se as medidas foram totalmente cumpridas e, assim, liberar o réu.

A análise dos processos permitiu concluir que quando o infrator paga as duas perícias, o processo demora, em média, dois anos menos. Logo, se a pessoa não tiver condições de pagar, terá que passar mais tempo "em débito com a justiça". Conclui-se, portanto, que a condição econômica do indivíduo se reflete na esfera judicial, pois, se o infrator possuir renda, ele poderá arcar com o valor da perícia e acelerar a marcha do processo. Relembra-se, aqui, que em relação aos agricultores, 
a situação de "estar respondendo a processo" possui uma série de repercussões de âmbito social, pois esse grupo compreende a dívida com quem quer que seja, mas principalmente com a justiça, como algo desabonador.

Compreende-se esse aspecto como uma oportunidade para refletir a respeito da isonomia jurídica, pois, neste caso, ter melhores condições econômicas representa resolver o problema de forma mais célere, e, portanto, ter menos aborrecimentos. Em lugar de buscar oferecer suporte aos que não podem pagar pelo serviço, seja por meio do aumento do número de funcionários, seja por meio de serviços voluntários ou estágio supervisionado, a Promotoria concede a "igualdade para os desiguais", pois admitindo a regra de "quem puder que pague", o que se obtém é uma profunda desigualdade conforme a qual quem tem mais renda, paga e livra-se do processo e quem tem menos continua "em débito" com o Estado, em função da própria ineficiência deste. Segundo Souza (2006, p.46), "para além da eficácia jurídica, existe uma espécie de acordo implícito em que alguns são considerados acima da lei e outros abaixo dela". Conforme Taylor (1989, p. 15) "para que haja eficácia legal da regra de igualdade é necessário que haja a percepção da igualdade na dimensão da vida cotidiana".

A própria constituição da relação processual demonstra a desigualdade e a desproporção que existe entre os sujeitos que a compõem. A doutrina jurídica retrata a relação processual por meio da figura de um triângulo, em cujos vértices estariam o Estado, o autor e o réu. Portanto, de um lado figuram profundos conhecedores das leis, portarias e resoluções, e, de outro, encontram-se pessoas despossuídas de conhecimento legal, ou mesmo, formal. O advogado tem a função de promover um nivelamento entre as partes. Mas de acordo com a lei, há situações em que não existe a obrigatoriedade da presença deste profissional ${ }^{4}$.

$\mathrm{Na}$ maioria dos processos analisados, os agricultores não estavam acompanhados por advogado. Na esfera cível estavam sozinhos e na esfera penal receberam o acompanhamento da defensoria pública. Acredita-se que esta seja uma das principais razões para justificar o fato de muitos desses agricultores aceitarem o TAC e, posteriormente, perceberem que não tinham condições de cumpri-lo. Nesse sentido, vale mencionar a fala do promotor de justiça, que ao descrever o perfil dos

\footnotetext{
${ }^{4}$ No Juizado Especial Cível, em causas de até 20 salários mínimos é facultativa a presença do advogado. No Juizado Especial Criminal , se a pessoa estiver desacompanhada de advogado receberá a assistência da defensoria pública ou de advogado dativo.
}

R. Inter. Interdisc. INTERthesis, Florianópolis, v.14, n.2, p.113-131 Mai.-Ago. 2017 
agricultores que respondem a processos disse: "O perfil é majoritariamente de pessoas pobres, até paupérrimas e desinstruídas, à mercê do suporte estatal".

O promotor também afirmou que, muitas vezes, o Ministério Público (MP) não propõe a realização do TAC, por compreender que essa forma de solução do conflito é mais rápida, mas pode suprimir algumas oportunidades de defesa do possível autor do fato. Disse ele: " (...) a razão que tem levado o MP de Viçosa a ingressar direto na justiça, sem convidar o degradador para um ajustamento de conduta é a constatação de que as pessoas sentem-se induzidas a assinar o termo e o fato. Quando o MP não celebra o termo de ajustamento de conduta e ingressa com a ação, ele tem que provar o fato e depois da condenação é que se é cobrada a reparação do dano. Fica demonstrado, então, que o TAC pula a etapa processual do conhecimento (em que são produzidas as provas), mas isso, muitas das vezes, não se mostra seguro".

Ainda a respeito da vulnerabilidade do agricultor em relação aos órgãos do poder judiciário, menciona-se ainda um conjunto de outros elementos, que também o compõem e o definem, e que contribuem para enfatizar a distância entre o órgão instituidor da normatividade e as partes a ela sujeitas. Trata-se do espaço físico, que, como ressalta Santos (1988), "nunca é só físico". O ambiente composto por mobiliário, computadores, carimbos, formulários, etc. representa um espaço de intimidação, pois é marcado pela presença de elementos que estão associados ao conhecimento e ao formalismo. As vestes e o vocabulário forenses também evidenciam a diferença entre os sujeitos e enfatizam a distância que existe entre eles.

Sobre o rigor indumentário do judiciário, Dolzany (2003) ressalta que talvez apenas as religiões tradicionais se comparem aos rigores dos paramentos dos rituais forenses. Para ele, um sacerdote e um juiz em suas vestimentas se confundem, pois em ambos os casos a veste cria um "ar" de superioridade. Em relação à linguagem, Dolzany (2003) afirma que "trata de um saber restrito a iniciados que não pode ou não deve ser vulgarizado", ou seja, a linguagem é uma forma de afirmação de poder.

Uma das características do linguajar jurídico que mais evidencia a distância das normas em relação aos seus destinatários é a ambiguidade. É comum em textos legislativos a presença de termos ambíguos e de conceitos indeterminados, que 
contribuem para deixar a sociedade mais passiva em aceitar e mais insegura em utilizar o que está na lei. Essas expressões deixam clara a intenção de manter as normas como instrumentos dos profissionais que possuem qualificação técnica para revelar seus significados. Segundo Lyra Filho (1982), a lei emana do Estado e permanece, em última análise, ligada à classe dominante, pois o Estado, como sistema de órgãos que regem a sociedade politicamente organizada, fica sob o controle daqueles que comandam o processo econômico, na qualidade de proprietários dos meios de produção.

Soares $(2007$, p. 8) observa que se a pessoa é prioridade na ordem de fundamento do Estado Brasileiro, esta necessita de condições para se desenvolver de forma plena e um requisito essencial é conhecer e compreender minimamente os seus direitos e deveres, o que pode se revelar uma verdadeira odisseia. Soares (2007, p. 8) afirma que a aproximação entre legislador e cidadão pode propiciar processos de produção do Direito em que haja mais persuasão e menos coerção. Neste ponto vale mencionar Freire (1983) que afirma que, de uma perspectiva realmente humanista, não cabe usar as técnicas para persuadir o camponês, como se ele fosse um papel em branco.

Souza (1988, p. 52) afirma que o direito oficial institucionalizou a função jurídica, que atomizou em relação às demais funções sociais. Segundo o autor, ocorreu uma "objetualização" dos sujeitos do processo, que se tornaram menos importantes do que o próprio processo. Desse modo, o judiciário apresenta intensa divisão de trabalho, inclusive entre funções práticas e funções intelectuais, com tarefas rígidas e hierarquicamente definidas. Nesse sentido, a padronização e o formalismo contribuem para produzir a sensação de impessoalidade e de legalismo.

$\mathrm{Na}$ mesma linha de raciocínio, Bourdieu (2003), compreendendo o direito como um poder simbólico, afirma que a ciência jurídica apreende o direito como um sistema fechado e autônomo, cujo desenvolvimento só pode ser compreendido segundo a sua dinâmica interna. Desse modo, segundo ele, os operadores do direito, desde a formação, são treinados a utilizar uma linguagem própria e hermética, que faz do direito um instrumento segregador, visto que é construído e utilizado por um grupo específico, que domina as técnicas. De acordo com esse raciocínio, o fato de as normas serem de difícil entendimento, não apenas assegura 
a esse grupo um campo de trabalho, como também facilita a aceitação das normas pela sociedade.

Para Bourdieu (2003), a linguagem jurídica traz em si o caráter de neutralidade e imparcialidade transparecendo que a decisão judicial representa a vontade do Estado e, por isso, aplica-se igualmente a qualquer um. O simbolismo evidencia que o agente atua ou fala em nome do Estado, e isto o legitima.

Segundo Souza, existe uma espécie de rede invisível que une desde o policial, na abertura do inquérito, até o juiz, na sentença final, passando por advogados, testemunhas, promotores, jornalistas etc (SOUZA, 2006, p. 46). Estes atores, por meio de um acordo implícito e jamais verbalizado, constroem o discurso da condenação ou da inocência, de acordo com as características do sujeito do caso. Nesse ponto também, é possível pensar o direito como um instrumento de poder.

\subsection{A INVISIBILIDADE DO CIDADÃO EM FACE DO PODER DO ESTADO}

Segundo Santos (2003), para ser considerado emancipatório, o direito precisa se adequar às reivindicações dos grupos sociais subalternos. A situação evidenciada por Santos (2003) também está presente na obra de Souza (2006), que afirma que uma característica marcante do desenvolvimento das sociedades de capitalismo periférico é a existência de um grande contingente populacional composto por marginalizados ou "desclassificados sociais". Estas pessoas ocupam um lugar periférico na sociedade e permanecem desvinculadas dos processos econômicos, sociais e políticos básicos. Segundo Souza (2006) um contingente enorme de indivíduos da sociedade brasileira não compartilha de um padrão mínimo de participação na esfera social que confere a dignidade e as condições mínimas de reconhecimento e respeito social que possibilitam formar da noção de cidadania em termos práticos e não apenas legais (SOUZA, 2006, p. 37).

Esses sujeitos que Souza (2006) classifica como "periféricos" são relegados à invisibilidade social, ou seja, não são vistos, não são ouvidos, não são notados, como se fossem menos cidadãos. Ainda que existam previsões legais sobre a igualdade fundamental entre os indivíduos, esses segmentos não desfrutam da igualdade assegurada porque não possuem reconhecimento, nem voz, nem acesso 
aos mecanismos de defesa e de obtenção das prestações de que necessitam. Não possuem, portanto, a condição de dignidade humana respeitada.

Taylor (1986) afirma que é a "dignidade" que possibilita a formulação da ideia de direitos individuais potencialmente universalizáveis a todos os indivíduos, mas a igualdade estabelecida nas leis e normas somente é eficaz no âmbito social se a percepção dessa mesma igualdade na vida cotidiana estiver efetivamente internalizada na sociedade (TAYLOR, 1986). Assim, Taylor procura encontrar na concepção de uma política de reconhecimento a saída para uma reelaboração da esfera pública que dê conta de atender as demandas que dizem respeito ao ideal de igualdade das democracias modernas e ao reconhecimento das especificidades das várias tradições culturais e das múltiplas formas de identidades constituídas historicamente.

A ideia é que o Estado crie políticas públicas que reconheçam as capacidades de tais indivíduos e deem a eles condições efetivas de exercer seus direitos, para que a dignidade não permaneça fundada no direito, sem que as pessoas possam de fato usufruir dela em razão das diferenças econômicas e sociais que existem na sociedade. Entretanto, historicamente esse reconhecimento não tem ocorrido.

A condição de subalterno (Santos, 2003), de sujeito periférico (Souza, 2006) protagonizada por alguns grupos sociais é evidenciada em muitos trabalhos que analisam o contexto socioeconômico brasileiro. Destaca-se, aqui, a condição semelhante assumida por grande parte dos agricultores familiares envolvidos nos processos estudados.

Para Martins (1986), no Brasil existe uma história urbana e os personagens desta história é que participam do pacto político, do qual o camponês é excluído e pelo qual é visto como um ator inferior, não essencial. Esse fato fez com que pouco se registrasse sobre o papel dos produtores de alimentos na construção do país, sendo o passado contado apenas sob a perspectiva da grande agricultura escravista, monocultora e de exportação - o ciclo do açúcar, o ciclo da borracha e o ciclo do café exemplificam essa tendência.

$\mathrm{Na}$ mesma linha, Altafin (2007) afirma que história dos produtores de alimentos no Brasil está ligada à trajetória de grupos que ocuparam a posição secundária dentro do modelo de desenvolvimento do país, pois enquanto a grande propriedade voltada à monocultura de exportação recebia estímulos e garantias dos 
governantes, esse mosaico de formas camponesas ligadas a cultivos alimentares dirigidos ao abastecimento interno era colocado à margem das políticas públicas.

\section{O SOCIAL PERIFÉRICO À LUZ DO PRINCÍPIO JURÍDICO DA DIGNIDADE HUMANA}

A condição de marginalidade e inferioridade que assola os agricultores familiares, não apenas no sentido social e econômico, mas que também se reflete na esfera jurídica, abre caminhos para reflexões no campo da dignidade humana, considerada atualmente um dos pilares do ordenamento jurídico, pois, ainda que existam previsões legais sobre a igualdade fundamental entre os indivíduos, esses segmentos não desfrutam da igualdade assegurada porque não possuem reconhecimento, nem voz, nem acesso aos mecanismos de defesa e de obtenção das prestações de que necessitam. Não possuem, portanto, a condição de dignidade humana respeitada.

O insucesso dos TAC impõe ao Ministério Público a obrigação de executar o acordo na esfera judicial. No Judiciário, os agricultores também encontram dificuldades que vão desde o comparecimento nas audiências, passando pela compreensão da linguagem forense, chegando até às limitações financeiras para cumprir as penalidades impostas.

De acordo com a doutrina jurídica, o patamar mínimo de que o cidadão necessita é compreendido como "mínimo existencial. Segundo Rawls (2001, p 166), "abaixo de um certo nível de bem-estar material e social, e de treinamento e educação, as pessoas simplesmente não podem participar da sociedade como cidadãos e, muito menos, como cidadãos iguais". A dignidade humana, direito fundamental e princípio máximo do estado democrático de direito, exige do Estado não só respeito e proteção, mas garantia das condições existenciais mínimas para uma vida saudável.

A Constituição brasileira, ao estabelecer a dignidade humana como fundamento da República, coloca esse princípio como base de sustentação de toda a estrutura jurídica e social. Segundo Sarlet (2001), o conceito de dignidade é algo que não pode ser definido abstratamente, mas apenas em concreto, à luz de um determinado ordenamento jurídico e dos influxos históricos e culturais de cada sociedade. Toda essa dificuldade teórica em identificar com precisão o conteúdo da 
dignidade humana decorre do fato de ser tal conceito indeterminado, ou seja, por ser vago e subjetivo, exige do intérprete a concretização de seu significado (SARLET, 2001). O que se pode afirmar ao certo é que o elemento cultural é indissociável da noção de dignidade. Além disso, há que considerar, ainda, que o conceito de dignidade tende a ser ampliado ou restringido por outros fatores, dentre os quais 0 econômico. Assim, em uma sociedade economicamente mais desenvolvida o conceito de dignidade - e, consequentemente, daquilo que a ofende - tende a ser mais alargado do que em outra menos desenvolvida (SARLET, 2001).

Sarlet (2001) observa que o direito exerce papel crucial na proteção e promoção da dignidade, embora ela não exista apenas onde é reconhecida pelo direito. Para o autor, quando se fala em "direito à dignidade", se está a considerar o direito ao reconhecimento, ao respeito, à proteção e a uma existência digna. Assim, de acordo com Sarlet (2005, p.30), a dignidade possui uma dimensão dúplice, que se manifesta, por um lado, como expressão da autonomia humana, e, por outro, como objeto sobre o qual deverá recair a obrigatória proteção e respeito, tanto por parte do Estado como por parte da comunidade.

Conforme Sarlet (2005, p.32), a dignidade da pessoa humana, manifesta-se, simultaneamente, como limite e tarefa dos poderes estatais e da comunidade em geral. Como limite, a dignidade implica não apenas que a pessoa não pode ser reduzida à condição de mero objeto da ação própria e de terceiros, mas também o fato de que a dignidade gera direitos contra atos que a violem ou a exponham a graves ameaças. Como tarefa, da previsão constitucional da dignidade da pessoa humana, decorrem deveres concretos de tutela por parte dos órgãos estatais, no sentido de proteger a dignidade de todos, assegurando-lhe também 0 devido respeito e promoção. (SARLET, 2005, p.32/33).

Vale aqui ressaltar que, de acordo com Bourdieu (2003), com frequência as frações sociais dominantes mascaram a existência de desvantagem entre os grupos sociais diversos, e, principalmente, que este fato seja inerente ao exercício da dominação classista. Ou seja, negam que exista uma ideologia da igualdade que serve de base ao consenso social e político, obscurecendo as relações de desigualdade.

Segundo Santos (2013), a forma jurídica burguesa constitui-se na especificidade de que o direito, nesta formação social, busca instituir a 
universalização dos interesses particulares da classe e de suas frações socialmente dominantes. Neste sentido, toda a formação social é mediada juridicamente para a manutenção e preservação do status quo do regime de classes.

Embora os ordenamentos normativos não sejam capazes de conceder dignidade, por ser o seu significado muito mais amplo do que um conceito jurídico, a existência de grupos sociais em posição de desvantagem aumenta a responsabilidade do poder judiciário, visto ser ele também responsável pela transposição do significado de dignidade que consta na lei, para a realidade.

\section{CONCLUSÕES}

Por meio desta pesquisa foi possível constatar que grande parte dos agricultores familiares da região em estudo fazem, de acordo com a lei ambiental, uso indevido da terra, e isto os coloca em situação vulnerável porque ficam sujeitos a uma autuação e, até mesmo, a um processo judicial, que pode trazer consequências que vão muito além do custo monetário ou do desgaste pessoal.

Embora o poder judiciário, com frequência, utilize mecanismos extrajudiciais para solução de tais problemas, como é o caso dos TACs (Termos de Ajustamento de Conduta) a posição de desvantagem dos agricultores frente ao poder do Estado foi evidenciada pela incapacidade de tais sujeitos utilizarem os mecanismos legais de defesa, como a defesa técnica realizada por advogado ou mesmo o acesso aos recursos. Ficou evidenciado, portanto, que a lei é elemento constitutivo dos meios de vida porque à medida que se apresenta como "geral e abstrata", "igual para todos" promove efeitos mais gravosos sobre aqueles que não possuem os acessos e as redes de relacionamento eficazes para Ihes garantir imunidade. Nesse sentido, a lei funciona como um elemento de poder, na linha apresentada por THOMPSON, SOUZA (2006), BOURDIEU (2003), e, como tal, em lugar de promover o tratamento equânime entre os diversos grupos sociais, amplia e reforça o histórico de exclusão, já existente nas esferas social e econômica. 


\title{
THE SOCIAL INVISIBILITY AND FAMILY FARMERS POLICY AND ITS CONSEQUENCES IN STATE RELATIONS
}

\begin{abstract}
:
This article aims to reflect about social invisibility and politics for some social segments, among which family farmers stand out, and also about the consequences of this invisibility in legal harvest verification, as this segment often faces legal conflicts from the breach of environmental legislation. The methodology applied in this study was public consultation to prosecutor files from Viçosa County, Minas Gerais, and process analysis. In conclusion, the social and political invisibility's work extends to the legal field because such social groups find it difficult not only to access information but also defense mechanisms.
\end{abstract}

Keywords: Invisibility. Family Farmers. State. Power. Legislation.

\section{LA INVISIBILIDAD SOCIAL Y POLÍTICA DE AGRICULTORES FAMILIARES $Y$ SUS CONSECUENCIAS EN LAS RELACIONES CON EL ESTADO}

\section{Resumen:}

Este artículo tiene como objetivo reflexionar sobre la invisibilidad social y política de algunos sectores de la sociedad, entre los que se destaca el de los agricultores familiares, y sobre los efectos de esta invisibilidad en el ámbito jurídico, ya que este sector se enfrenta a muchos conflictos judiciales debido a infracción de la legislación ambiental. La metodología utilizada en el estudio consistió en consultar los archivos del Ministerio Público en el municipio de Viçosa, estado de Minas Gerais y en analizar los procesos judiciales. De ello se concluye que la invisibilidad social y política se extiende al ámbito jurídico debido a que estos grupos sociales tienen dificultades para acceder no sólo a la información, sino también a los mecanismos de defensa.

Palabras clave: Invisibilidad. Agricultores familiares. Estado. Poder. Legislación 


\section{REFERÊNCIAS}

ALTAFIN, lara. Reflexões sobre o conceito de agricultura familiar. Brasília:

CDS/UnB, 2007.

BARROSO, Luís Roberto. Grandes Transformações do Direito Contemporâneo e o Pensamento de Robert Alexy. Conferência em Homenagem a Robert Alexy. 2014. Disponível em: http://conjur.com.br., Acesso em novembro de 2013.

BOBBIO, Norberto. O positivismo jurídico: lições de filosofia do direito. São Paulo: Ícone, 1995.

BOURDIEU, Pierre. 0 poder simbólico. 6 ed. Rio de Janeiro: Bertrand Brasil, 2003.

DOLZANY, Marcelo. A comunicação e o acesso à Justiça. R. CEJ, Brasília, n. 22, p. 13-19, jul./set. 2003.

FRANCO, Maria Sylvia de Carvalho. Homens livres na ordem escravocrata. $4^{\text {a }}$ ed. São Paulo: Fundação Editora da UNESP, 1997.

FREIRE, Paulo. Pedagogia do oprimido. Rio de Janeiro: Paz e Terra, 1983.

LEMOS, Luís Fernando Bittencourt de. A Teoria da Norma Jurídica de Tercio Sampaio Ferraz Junior. Monografia apresentada ao Departamento de Direito Público e Filosofia do Direito da Faculdade de Direito da Universidade Federal do Rio Grande do Sul. Porto Alegre, 2011.

LYRA FILHO, R. O que é Direito. $11^{\text {a }}$ ed. São Paulo: Brasiliense, 1982.

RAWLS, J. Justice as Fairness: a restatement. Cambridge: Harvard University Press, 2001.

MARTINS, José de Souza. Os camponeses e a política no Brasil. Petrópolis: Vozes, 1986. 
NAVARRO, Zander; PEDROSO, Maria Theresa M. A agricultura familiar no Brasil: da promessa inicial aos impasses. Rev. Econ. NE, Fortaleza, v. 45, suplemento especial, p. 7-20, out./dez., 2014.

SANTOS. Boaventura de Sousa. 0 discurso e o poder: ensaio sobre a sociologia da retórica jurídica. Porto Alegre: Fabris, 1988.

SANTOS. Boaventura de. Poderá o Direito ser emancipatório? Revista Crítica de Ciências Sociais, n. 65, maio de 2003, p. 3-76.

SARLET, Ingo Wolfgang. A eficácia dos direitos fundamentais. $2^{\mathrm{a}}$ ed. Porto Alegre: Livraria do Advogado, 2001.

SCHNEIDER, Sérgio; NIEDERLE, Paulo André. Agricultura familiar e teoria social: a diversidade das formas familiares de produção na agricultura. In: FALEIRO, F. G.; FARIAS NETO, A. L. (Org.). Savanas: desafios e estratégias para o equilíbrio entre sociedade, agronegócio e recursos naturais. Planaltina: Embrapa Cerrados, 2008, p. 989-1014.

SOARES, Fabiana de Menezes. Legística e desenvolvimento: a qualidade da lei no quadro da otimização de uma melhor legislação. Cadernos da Escola do Legislativo, Belo Horizonte, v. 9, n. 14, p. 7-33, jan./dez. 2007.

SOUZA, Jessé. A construção social da subcidadania: para uma sociologia política da modernidade periférica. Belo Horizonte, Editora da UFMG, 2006.

STRECK, Lenio Luiz. Hermenêutica Jurídica e $(m)$ Crise. $11^{\text {a }}$ ed. Porto Alegre: Livraria do Advogado, 1998.

SUNDFELD, Carlos Ari. Fundamentos de Direito Público. $4^{\circ}$ ed. $7^{\circ}$ tiragem. Ed. Malheiros: São Paulo, 2006.

SUNDFELD, Carlos Ari. Fundamentos de Direito Público. $4^{\mathrm{a}}$ ed. $7^{\circ}$ tiragem. Ed. Malheiros: São Paulo, 2006.

TAYLOR, Charles. Sources of the Self: The Making of the Modern Identity , Harvard University Press, Cambridge, 1989, tradução brasileira: As Fontes do Self: A construção da Identidade Moderna, Loyola, São Paulo, 1997

THOMPSON, E. P.. Senhores e caçadores. Rio de Janeiro: Paz e Terra, 1987. 
VAN DER PLOEG, Jan D. Sete teses sobre a agricultura camponesa. In:

PETERSEN, Paulo (Org.). Agricultura familiar camponesa na construção do futuro.

Rio de Janeiro: AS- PTA, 2009, p. 17-31.

Artigo:

Recebido em 06 de Setembro de 2016.

Aceito em 27 de Novembro de 2016.

R. Inter. Interdisc. INTERthesis, Florianópolis, v.14, n.2, p.113-131 Mai.-Ago. 2017 